\title{
NURTURING PROACTIVE, CREATIVE AND COMMUNICATIVE LEARNERS THROUGH SOCIAL MEDIA
}

\author{
Christopher Pang, Xiu Er, Chuang and Christian Chia \\ Nanyang Polytechnic, Singapore
}

\begin{abstract}
The study investigates the effectiveness of using social media, within a self-determined or personalised learning environment, to nurture proactive, creative, and communicative learners with high self-efficacy and autonomy. Research has shown that interactivity, collaboration, learner negotiation and personalisation enabled by Web 2.0 can spur developmental growth of communication skills. Using a quasi-experiment with pre- and post-tests involving 184 business students taking Effective Writing Skills, the study found that a self-determined, personalised learning environment resulted in students demonstrating higher levels of pro-activity, autonomy and creativity that contributed to the growth of communication capabilities, when compared to control groups. It was also noted that peer influence could significantly affect communication outcomes in a social media enhanced learning environment. This study is significant because it examines how communication skills can be developed through the educational use of social media. It also addresses the demand to produce graduates with strong communicative skills. The research outcomes of this study can inform pedagogical practice in preparing future-ready articulate graduates.
\end{abstract}

Keywords: Social Media, Self-Determined Learning, Learner Autonomy, Writing Skills

\section{Introduction}

Communication skills, as defined as oral and written abilities, have been repeatedly flagged by employers and even members of parliament, as generally lacking in local tertiary graduates - a problem that is experienced by both universities and polytechnics in Singapore. Thus, there is an urgent need to address the achievement gap in linguistic productive skills, particularly at the tertiary level. Strong communication skills remain a desired competence employers want, especially in a highly connected and always connected workplace. The workplace is also evolving as organisationsutilise a plethora of technologies across a wide spectrum of industries, sectors and roles. A future-ready graduate thus, has to cope not only with a fast changing economic landscape but also with one where technology is used pervasively. Communication skills as well as digital literacy skills are so tightly intertwined to the extent that they almost need to be taught as a unified whole. The educational use of social media, therefore, has a role in this new future state of affairs. This is significant as strong communication skills are a critical attribute of a future-ready graduate.

A review of current research suggests that proactivity and interactivity, which are dimensions associated with Web 2.0, can spur further developmental growth in communicative abilities (Kao and Craigie, 2014; Suthiwartnarueput and Wasanasomsithi, 2012; Yu, 2014). Communication skills also require self-practice, which underpins the importance of learner autonomy (Omar, Embi and Yunus, 2012), where learners are required to take responsibility of their learning. The advent of Web 2.0 also requires a shift towards personalisation if students are to become strong communicators. So, a pedagogical model that addresses the achievement gap in communication skills could potentially lead to more articulate graduates. Therefore, exploring pedagogical approaches that support self-determined and personalised learning are critical in achieving identified outcomes and desired competencies. Self-determined and personalised learning share a natural affinity with learning via social media or new media. This is because of social media's ability to engender expressiveness and develop authorial voices, which is key to becoming proficient communicators. Most students are also bored with school. The repetitive nature of school and its predictable routines may build discipline but it may also contribute to rote, and almost robotic learning (Kao and Craigie, 2014). Allowing students a greater say in their own education, makes it more personalised, which could potentially lead to students taking a more active, rather than passive role in learning. Hence, this research can potentially transform learning about language and communication at the tertiary level.

Corresponding Author:Christopher Pang / chris_pang@nyp.edu.sg 


\section{Literature Review}

Web 2.0, characterised by social collaboration and personalisation has brought about new ways of connecting and networking. It has also introduced new ways of learning and has far-reaching implications of how education is transforming and will be transformed. The challenge therefore, is how educators will respond to this new era of hyper-communicative social media platforms in terms of developing new pedagogical models, or in short, a Pedagogy 2.0 to leverage new media technology.

\section{Self-determined Learning in the Web 2.0 Era}

To facilitate this, Cochrane $(2010,2012)$ believed that it will require two ontological shifts: 1 . Re-categorising social media from the domain of informal social interactivity to collaborative tools that enable new pedagogical designs (Kukulska-Hulme, 2010; Laurillard, 2007, 2012), and 2. Re-categorising teaching and learning from teacher-directed pedagogy to enabling student-determined (or negotiated) learning, which has been termed heutagogy (Blaschke, 2012; Hase and Kenyon, 2007; Luckinet al., 2010). A heutagogical learning environment facilitates development of capable learners and emphasises both the development of learner competencies as well as development of the learner's capability and capacity to learn (Ashton and Newman, 2006; Bhoryrubet al., 2010; Hase and Kenyon, 2007). Selwyn (2010) also highlighted the emergence of "user-driven" education as enrolled students are already highly connected, collective, and creative.

\section{Technology-mediated Language Learning}

Many educational researchers and practitioners have shown that technology can benefit language teaching and learning (Jamieson, Chapelle, and Preiss, 2005; Warschauer and Healey, 1998). In particular, Web 2.0 tools hold the promise to promote collaboration and interaction among users (Wang and Vasquez, 2012). Language learners can develop their autonomy to improve language skills through Web 2.0 tools (Lee, 2011; Lomicka and Lord, 2012). This is achieved through a combination of factors. Social media usage and interactions reduce language barriers and social inhibitions (McCarthy, 2010). Lomicka and Lord (2012) found that the use of social networking sites (SNS) could help learners build collaborative communities and provide opportunities for creative language practice outside of class time. Students could also develop autonomy in their learning and grow their identity through interactions on SNS (Halvorsen, 2009).

The use of social media to improve language or communication proficiency has also its fair share of detractors. The challenge for using social media in the classroom points to it being a source of distraction, which can be detrimental to student performance (Mao, 2014). The use of social media also blurs the lines between social entertainment and intellectual engagement, which can diminish productive learning (Fewkes and McCabe, 2012). Researchers also reported that the use of social media in educational settings did not mirror personal usage in terms of active participation (Jones et al., 2010).

The research focus gathered from this review, can be positioned as being centredaround the educator's or researcher's desire to transfer the inherent interactivity from social media into subject domains. Whether an intervention succeeds or fails may actually hinge on students exercising their freedom of choice to participate willingly on social media created for educational purposes. This choice can 'make or break' the educational use of social media and warrants further investigation. While it is laudable to elucidate the effects on student learning when social media is integrated, it is equally important to look at how willingness translates to readiness on the students' part. Integral to this line of reasoning is how a self-determined or personalised learning environment can better achieve this.

Therefore, the study examines the following:

- How does applying self-determined learning principles through social media create a personalised learning environment that promotes proactivity and learner autonomy?

- How does the use of social media in a personal learning environment promote the creative use of language for business communication?

- What is the impact of the educational use of social media on business writing skills, in terms of outcomes and performance? 


\section{Methodology}

The study involved an intervention and used a quasi-experiment design with pre- and post-tests and a control group. Eight Year One classes from a polytechnic in Singapore taking Effective Writing Skills were involved in the study. Four classes were assigned as experimental groups while the remaining groups acted as the control groups. The experimental groups received the intervention while the control groups received traditional instruction. The class sizes were similar at between 21 to 24 students per class. Full-time tutors with at least three years' experience taught these classes. Students were of similar profiles at ages between 18 to 22 years old and have passed a standardised English as a First Language test at the secondary level.

The pre- and post-tests were timed writing proficiency tests scored using rubrics. In the pre-test, students had to identify errors and edit a passage in 60 mins. In the post-test, students completed two professional writing tasks. Two self-reported questionnaires were administered at the start and at the end of the intervention. The first questionnaire measured social media habits and self-perceived language proficiency, learning preferences and self-directedness characteristics. The second questionnaire measured levels of proactivity and self-determined learning characteristics. In addition, the post-tests on professional writing proficiency were also coded for creative expression through content analysis.

\section{Intervention Design}

This study uses an intervention that incorporated self-determined learning principles to allow for a personalised learning environment mediated by social media. The intervention lasted eight weeks and covered professional writing. The control groups continued with the traditional, diathetic face-to-face tutorials with classroom activities and elearning modules hosted on Blackboard (a learning management system). The intervention was developed based on Blaschke and Kenyon's design guidelines (2016) that advocated: - A degree of ownership to determine what and how they learn (this itself a Web 2.0
characteristic);
-
- The opportunity to negotiate the nature of assignments to complete;
-
-
A personal learning environment that is technology-mediated;
goals;
Embracing technology and use of social media's collaborative tools to achieve negotiated
-

transformed learning intervention.

Table 1 Self-determined versus traditional learning design.

- Traditional

\footnotetext{
- Self-determined

- Learning Contract - Explanation of Writing Principles and Strategies

- Explanation of Writing Principles and Strategies - Facilitated Writing Coaching Sessions

- Facilitated Writing Coaching Sessions - Review of Reference Text Examples

- Online Review of Professional Writing - Tutor-led Practice Exercises

- Democratic Decision to Decide Class Delivery - Discussion of Past Test Questions Dates and Formats

- Co-created Learning

- Online and In-class Student-led Practice Exercises

- Online and In-class Discussion for Past Test Questions

- Online Self-Reflection
} 


\section{Findings}

\section{Social Media Habits}

The pre-questionnaire reported similar social media habits and Table 2 shows the profiles of the experimental and control groups.

Table 2 Social Media Habits

\begin{tabular}{llc}
\hline & $\begin{array}{c}\text { Experimental } \\
\mathrm{n}=81\end{array}$ & Control \\
& $\mathrm{n}=86$ \\
\hline Average no. of years using social media & 5.1 & 5 \\
\hline Access social media per day (median) & Less than 5 times/day \\
\hline $\begin{array}{l}\text { Average no. of hours spent on social } \\
\text { media per day }\end{array}$ & 1.3 & 1.3 \\
\hline
\end{tabular}

About $50 \%$ of students across both groups reported they had more than 6 years of experience using social media. This would mean students have started on social media in their pre-teen years at the primary school level. What was surprising was the sizable number of students who reported not having a Facebook account (experimental $=15.1 \%$, control $=19.8 \%$ ). When asked, students stated that they were active users of Instagram (mobile photo-sharing application) and Snapchat (messaging application with self-deleting posts). The social media habit questionnaire also found that about half of the students do not have a Facebook account dedicated to schoolwork. Tutors reported that they had to allocate time for students to set up their Facebook accounts. The ever-changing ephemeral preferences among young digital natives is evident here.

\section{Student Learning Profiles}

Students in both groups were asked to rate, along a 5-item Likert scale, their perceived writing proficiency, learning preferences and likelihood of carrying out self-directed, outside the classroom activities. Table 3 shows the comparison between both groups.

Table 3 Perceived proficiency, preferences, self-directed performance and pre-test scores

\begin{tabular}{lll}
\hline & $\begin{array}{l}\text { Experimental } \\
\mathrm{n}=86\end{array}$ & $\begin{array}{l}\text { Control } \\
\mathrm{n}=81\end{array}$ \\
\hline Perceived writing proficiency & 2.85 & 2.55 \\
\hline Learning format preferences & & \\
$\quad$ Online & 3.2 & 3.3 \\
In-class & 3.2 & 3.3 \\
Group-based & 3.2 & 3.4 \\
\hline Self-directed performance & 2.7 & 2.8 \\
\hline Pre-test score & $71.7 \%$ & $69.3 \%$
\end{tabular}

Statistical tests reported no significant differences between the experimental and control groups. Both groups were generally similar. They did not show any clear preference for any particular delivery formats and were less likely to perform activities beyond assigned tasks necessary to complete modular pass requirements. The Perceived writing proficiency was tied to students' pre-test scores. As students had completed graded assignments prior to the start of the intervention, students based their perceptions of their writing abilities on these scores. The difference in pre-test scores between the experimental and control was not statistically significant. 


\section{Proactivity}

Proactivity was defined as students' follow-up and follow-through during and after each class. Students were asked to rate if they would engage the tutor for additional coaching, would follow up on assignments beyond class time. An independent-sample $t$ test was conducted to test if students were more proactive in a selfdetermined learning environment as opposed to a traditional face-to-face tutorial with elearning. As shown in Table 4, the test was significant, $t(152)=5.08, \mathrm{p}<.05$. Students in the self-determined learning environment $(\mathrm{M}=3.19, \mathrm{SD}=.90)$ on the average were more likely to engage the tutor for coaching and follow-up on learning assignments than those in traditional settings $(\mathrm{M}=2.49, \mathrm{SD}=.08)$.

Table 4 Students' proactivity levels

\begin{tabular}{lccll}
\hline & $\mathrm{N}$ & Mean & $\begin{array}{l}\text { Std. } \\
\text { Deviation }\end{array}$ & $\mathrm{T}$ \\
\hline Experimental & 75 & 3.19 & .90 & $5.709 * *$ \\
\hline Control & 79 & 2.49 & .80 & \\
\hline$* * \mathrm{p}<.01$ & & & &
\end{tabular}

\section{Self-determined Learning Characteristics}

Self-determined learning characteristics were identified as students' willingness to propose topics to tutors, negotiating tasks and if students felt they had a sense of control of their own learning. It can be viewed as exhibiting a greater sense of active ownership in the learning process and learner autonomy. An independentsamplet test was conducted to test if students exhibited self-determined learning characteristics as opposed to a traditional face-to-face tutorial with elearning. As shown in Table 5, the test was significant, $t(152)$ $=8.326, \mathrm{p}<.01$. Students in the self-determined learning environment $(\mathrm{M}=3.76, \mathrm{SD}=.71)$ on the average felt more in control of their own learning and were more autonomous than those in traditional settings $(\mathrm{M}=2.84, \mathrm{SD}$ $=.67)$.

Table 5 Students'self-determined learning characteristics

\begin{tabular}{lccll}
\hline & $\mathrm{N}$ & Mean & $\begin{array}{l}\text { Std. } \\
\text { Deviation }\end{array}$ & $\mathrm{T}$ \\
\hline Experimental & 75 & 3.76 & .71 & $8.326^{* *}$ \\
\hline Control & 79 & 2.84 & .67 & \\
\hline$* * \mathrm{p}<.01$ & & & &
\end{tabular}

\section{Creativity}

Creativity was operationalised as creative cognition and coded using properties of idea generation, practicality and causality, which were relevant to the professional writing pro-test. Idea generation was defined as the ability to generate ideas that were original or novel, evidenced by an articulated perspective or line of reasoning. Practicality was defined as the ability to plan and write pragmatic messages that solve authentic instructional challenges using recommended writing strategies. Causality was defined as the degree of how well ideas and explanations achieved persuasive outcomes. Three coders were involved and the inter-coding reliability using Krippedorf's Alphas was 0.86, which was deemed an acceptable rating.

An independent-sample $t$ test was conducted to test if students were more creative cognitively in a selfdetermined learning environment as opposed to a traditional and more structured class delivery. As shown in Table 6 , the test was significant, $t(182)=1.98, \mathrm{p}<.05$ for idea generation. The test was also significant, $t(182)$ $=2.026, \mathrm{p}<.05$ for practicality. Students in the self-determined learning environment generated more ideas and offered pragmatic solutions to address a problem. However, the test was insignificant, $t(182)=1.811, \mathrm{p}<.05$ for causality. 
Table 6 Students' creativity cognition levels

\begin{tabular}{lccll}
\hline & $\mathrm{N}$ & Mean & $\begin{array}{l}\text { Std. } \\
\text { Deviation }\end{array}$ & $\mathrm{t}$ \\
\hline Experimental & 92 & & & \\
Idea Generation & & 3.64 & 1.36 & $1.982^{*}$ \\
Practicality & & 3.98 & 1.06 & $2.026^{*}$ \\
Causality & & 3.84 & 1.13 & 1.811 \\
\hline Control & 92 & & & \\
Idea Generation & & 3.25 & 1.32 & \\
Practicality & & 3.65 & 1.12 & \\
Causality & & 3.52 & 1.22 & \\
\multicolumn{1}{c}{$* \mathrm{p}<.05$} & & &
\end{tabular}

\section{Discussion}

The findings on the educational benefits of a self-determined, personalised learning environment are consistent with other research studies done on social media and communicative abilities. Active use of social media facilitated deeper thinking and understanding though the evaluation of personal preferences via self-reflection (Blaschke, 2012). Another similar finding revolved around how communication and connectedness between peers and tutors also improved significantly (Halvorsen, 2009; Wang and Vasquez, 2012). Students also demonstrated greater autonomy and independence. A self-determined learning environment encouraged students to follow through on a heightened ownership of learning to proactively taking charge of their own learning. An ownership of the learning process also activated a greater sense of responsibility and maturity. Initially, when students were given the option to determine the delivery and format of classes, tutors reported that their classes suggested cancelling all face-to-face tutorials. As students deliberated, they opted for a varied delivery approach - a mix of face-to-face and virtual classes. When asked why, students upon reflecting wanted a variety of delivery styles, as they were bored with a repetitive delivery mode. Students also opted for optional face-to-face classes instead of cancelling all classes as they recognised that it was also important to cater to those who preferred face-to-face sessions. As a result, students were more engaged as they were able to express their learning preferences and there was sufficient room for negotiating a differentiated delivery. In addition, students were also more comfortable proposing topics they would like covered, to their tutors and charting their own and the class' learning paths. The negotiated curriculum, thereby, provided an unexpected benefit of tailoring learning for a wider cross section of students, making learning more personal and relevant. This also resulted in students outperforming their peers in the control groups.

Blaschke (2012) further explained that when students recognised the relevance of a social media learning activity, they exhibited increased cognitive engagement. This focus on relevance is significant. Besides making learning more relevant to the individual, learning activities must also be relevant to the medium. Porting an existing activity and expecting it to have immediate active participation is unlikely to work in social media. This is an important issue to address. Tailoring learning activities to appeal to students' preference for social mediaready content is critical to lesson success. A review of the postings showed that students were more likely to respond to an activity if their comments would be read when shared. In fact, students pointed out the response time from tutors was often too slow - they expected an instantaneous response as they would on any regular social media platforms they use. Using social media thus automatically resulted in a heavier workload on tutors outside regular office hours. Also, the viral-ness of an activity and its potential for comments to be reposting was also a factor for consideration. Students posted solutions and exercises that maximised the potential of being liked, shared and reposted and prioritised this attribute over a solution that educators might prefer instead. This presents a pedagogical challenge for educators. If educators take the stand that learning content designed to fulfil a desired outcome should come first (pedagogy before technology), they run the risk of lowered and disengaged participation. The situation becomes more acute as there is the possibility of content and activities being seen as unattractive and dull, when viewed in social media terms. If educators first set up a social media as a learning medium and populate it with content and activities (technology before pedagogy), they run the risk of creating a pedagogically unsound learning model that emphasises instruction and interaction over outcomes. 
The obvious solution is of course, to integrate the two. That is easier said than done. Even though this study attempted to integrate pedagogy with technology, not all blended tutorials and the activities were wholly successful. The more successful activities made use of the collaborative nature of social media and provided the opportunity to create social-media-worthy postings. The less successful examples also followed a similar vein integrating pedagogy and technology but did not enjoy the same level of participation due to a perceived lack of relevance and attractiveness. In analysing why such activities failed to elicit the sought-after active participation on social media, it was observed that the initiation of postings by opinion leaders was key. If the students whom the classes perceived as peer opinion leaders posted first, it was more likely to enjoy greater participation. This is not unlike what current online influencers e.g. bloggers with sizable followers, do in popular social media sites. It was observed that there was also a normalising effect on subsequent postings that followed the opinion leaders' posts. Even in the educational use of social media, the leaders-and-followers phenomenon appears to influence discussion and activity levels.

In cultivating student communication skills, the use of social media presents a unique opportunity that allows for solving problems collaboratively in small groups, larger teams or an entire learning community. This emerged phenomenon has been suggested by numerous studies examining the potential of using social media for collaborative problem solving within a blended learning environment (Radwan, Ballera, and Ateya, 2015). In our study, the students' increased creative cognition in terms of idea generation and practicality of solutions were significantly better than their peers. Tutors reported a more astute handling of communicative tasks and a heightened ability to articulate the solution relevant to the presented situation and intended recipients.

The use of social media also showcased the affinity for technology-mediated learning by students as digital natives. Students were able to propose more efficient ways to invite classmates into the Facebook writing groups (not a single email invite was sent and it was done quickly and effortlessly using a snowball approach). They also exhibited clear expertise in using Facebook's ability to track the history of a conversation and revisions in documents for use in comparing different drafts and learning from revised writing improvements. In fact, when students were elected as the groups' moderators, at times they prove themselves to be more capable and responsive than their tutors. The use of social media allowed students to step up and own the learning process too.

\section{Conclusion and Future Direction}

The use of social media within a self-determined learning environment holds promise in several areas. The first is the collaborative platform allowed for a negotiated curriculum that offered more relevant and differentiated learning. The second is the increased learning ownership as it promotes autonomy and independence. These are essential qualities necessary for cultivating proactive learners. The third area is the opportunity to co-create learning activities in small groups and as a class. This opportunity is a result of two factors -1 ) social media itself offers the modal flexibility for negotiating a shared curriculum and 2) the collaborative learning aspect that allows for a public showcase, easy sharing and instant distribution of solutions within a learning community.

There are also several areas for future studies. The effect of peer opinion leaders when social media is used educationally warrants further investigation. Another area of interest is how the use of social media impacts individual and group-based assessments as ideas, solutions and perspectives are rapidly. Overall, this study presents important considerations for any educator seeking to leverage social media and provides some insights and possibilities for designing a curriculum and associated learning activities.

\section{References}

Ashton, J. and Newman, L., 2006. An unfinished symphony: 21st century teacher education using knowledge creating heutagogies. British Journal of Educational Technology, 37(6), pp.825-840.

Blaschke, L.M. and Hase, S., 2016. Heutagogy: A holistic framework for creating Twenty-First-Century selfdetermined learners. In The Future of Ubiquitous Learning (pp. 25-40). Springer Berlin Heidelberg.

Blaschke, L.M., 2012. Heutagogy and lifelong learning: A review of heutagogical practice and self-determined learning. The International Review of Research in Open and Distributed Learning, 13(1), pp.56-71. 
Bhoyrub, John, John Hurley, Gavin R. Neilson, Mike Ramsay, and Margaret Smith. "Heutagogy: An alternative practice based learning approach." Nurse Education in Practice 10, no. 6 (2010): 322-326.

Cochrane, T., 2012. Anmlearning journey: mobile web 2.0 critical success factors. International Journal of Handheld Computing Research (IJHCR), 3(2), pp.44-57.

Cochrane, T.D., 2010. Exploring mobile learning success factors. Alt-j, 18(2), pp.133-148.

Fewkes, A.M. and McCabe, M., 2012. Facebook: Learning tool or distraction?.Journal of Digital Learning in Teacher Education, 28(3), pp.92-98.

Halvorsen, A., 2009. Social networking sites and critical language learning. Handbook of research on Web 2.0 and second language learning, pp.237-258.

Hase, S. and Kenyon, C., 2007. Heutagogy: A child of complexity theory. Complicity: An International Journal of Complexity and Education, 4(1).

Jamieson, J., Chapelle, C.A. and Preiss, S., 2005. CALL evaluation by developers, a teacher, and students. CALICO journal, pp.93-138.

Jones, N., Blackey, H., Fitzgibbon, K. and Chew, E., 2010. Get out of MySpace!.Computers \& Education, 54(3), pp.776-782.

Kao, P.C. and Craigie, P., 2014. Effects of English usage on Facebook and personality traits on achievement of students learning English as a foreign language. Social Behavior and Personality: an international journal, 42(1), pp.17-24.

Kukulska-Hulme, Agnes. 2010. Mobile learning as a catalyst for change. Open Learning: The Journal of Open and Distance Learning, 25(3) pp. 181-185.

Laurillard, D., 2013. Teaching as a design science: Building pedagogical patterns for learning and technology. Routledge.

Lee, L., 2011. Blogging: Promoting learner autonomy and intercultural competence through study abroad. Language Learning \& Technology, 15(3), pp.87-109.

Lomicka, L. and Lord, G., 2012. A tale of tweets: Analyzing microblogging among language learners. System, 40(1), pp.48-63.

Luckin, R., Clark, W., Garnett, F., Whitworth, A., Akass, J., Cook, J., Day, P., Ecclesfield, N., Hamilton, T. and Robertson, J., 2010. Learner-generated contexts: A framework to support the effective. Web 2.0-Based ELearning: Applying Social Informatics for Tertiary Teaching: Applying Social Informatics for Tertiary Teaching, p.70.

Mao, J., 2014. Social media for learning: A mixed methods study on high school students' technology affordances and perspectives. Computers in Human Behavior, 33, pp.213-223.

McCarthy, J., 2010. Blended learning environments: Using social networking sites to enhance the first year experience. Australasian Journal of Educational Technology, 26(6).

Omar, H., Embi, M.A. and Yunus, M.M., 2012. ESL learners' interaction in an online discussion via Facebook. Asian Social Science, 8(11), p.67. 
Radwan, A., Ballera, M., \&Ateya, I. L. 2015. Collaborative problem solving using public social network media: analyzing student interaction and its impact to learning process. International Journal of Digital Information and Wireless Communications, 3(1): 25-42

Selwyn, N., 2010. Looking beyond learning: Notes towards the critical study of educational technology. Journal of Computer Assisted Learning, 26(1), pp.65-73.

Suthiwartnarueput, T. and Wasanasomsithi, P., 2012. Effects of using Facebook as a medium for discussions of English grammar and writing of low-intermediate EFL students. Electronic Journal of Foreign Language Teaching, 9(2), pp.194-214.

Wang, S. and Vasquez, C., 2012. Web 2.0 and second language learning: What does the research tell us. Calico Journal, 29(3), pp.412-430.

Warschauer, M. and Healey, D., 1998. Computers and language learning: An overview. Language teaching, 31(02), pp.57-71.

Yu, L.T., 2014. A case study of using Facebook in an EFL English writing class: The perspective of a writing teacher. JALT CALL Journal, 10(3), pp.189-202. 